Post-print version: Pedro Lastra-González, Miguel A. Calzada-Pérez, Daniel Castro-Fresno \& Irune Indacoechea-Vega (2018) Asphalt mixtures with high rates of recycled aggregates and modified bitumen with rubber at reduced temperature, Road Materials and Pavement Design, 19:6, 1489-1498, DOI: 10.1080/14680629.2017.1307264

\title{
1 Asphalt mixtures with high rates of recycled aggregates and modified 2 bitumen with rubber at reduced temperature
}

3 Pedro Lastra-González ${ }^{\mathrm{a},{ }^{*}}$, Miguel A. Calzada-Pérez ${ }^{\mathrm{b}}$, Daniel Castro-Fresno ${ }^{\mathrm{a}}$, and Irune Indacoechea4 Vega $^{a}$

a GITECO Research Group, Universidad de Cantabria. Avda. de Los Castros s/n., 39005 Santander, Spain.

\author{
Daniel Castro-Fresno \\ Irune Indacoechea-Vega
}

castrod@unican.es

irune.indacoechea@unican.es

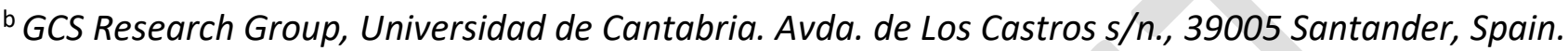
Miguel A. Calzada-Pérez

calzadam@unican.es

* Corresponding author: Pedro Lastra-González. E-Mail: pedro.lastragonzalez@unican.es

Tel.: +34942203943 / Fax: +34942201703

\section{Abstract}

An asphalt concrete and a very thin asphalt concrete have been designed with more than $80 \%$ of alternative aggregates (primary slag of electric arc furnace and RAP). A modified bitumen with rubber from end-of-life tires, and a fatty acid amide wax to decrease the manufacturing temperature were used. The process of manufacturing has been carried out at the easiest way.

Both mixtures were manufactured at conventional temperature without wax $\left(170^{\circ} \mathrm{C}\right)$, and at reduced temperature when the wax was incorporated $\left(150^{\circ} \mathrm{C}\right)$. Their mechanical and dynamic performance was compared. The resistance against plastic deformation and the effort that has to be made for the compaction of the mixtures modified with the wax at reduced temperature did not change, but the indirect tensile strength ratio decreased. The stiffness in the mixtures with wax was slightly higher, and there were not significant differences in the resistance to fatigue, although it seemed to decrease when the wax was added.

22 Keywords: Asphalt concrete; Rubber; Slag; RAP; Wax; Modified mixture.

\section{Introduction}

Bituminous mixtures are nowadays a useful tool to reuse by-products as slags, waste materials as RAP, and waste polymers as rubber from end-of-life tires (ELT). This paper gathers the implementation of some of the most popular advances in the same mixture. These advances have been carried out at easy way trying to demonstrate that their application, currently, does not depend on technical factors. Besides, as the use of rubber to modify bitumen increases its viscosity (1), two waxes have been selected with the aim to decrease the manufacturing temperature(2).

An asphalt concrete (AC 16S) and a very thin asphalt concrete (BBTM 11B) have been designed replacing at least $80 \%$ of their natural aggregate by RAP and electric arc furnace (EAF) slag, and using a rubber modified bitumen.

33 Although the use of RAP in surface layers is forbidden in some countries, the research about its use is currently aimed towards the use of $100 \%$ of RAP $(3,4)$. Besides, Warm Mix Asphalts (WMA) with high percentages of $\operatorname{RAP}(5,6)$ have been developed in some studies, although its use is usually linked 
with foaming and the application of emulsions. EAF slag is an alternative to replace natural aggregate, especially the coarse fraction(7, 8, 9), and it can work together with $\operatorname{RAP}(10,11)$. The bitumen modified with rubber from ELT can reach similar properties than those modified with polymers(12).

To decrease the manufacturing temperature of the mixture two waxes have been studied. These waxes are usually employed with conventional bitumen to develop warm mixtures, although a study carried out with synthetic wax and a bitumen with $10 \%$ of rubber concluded that over the melting point of the wax $\left(110^{\circ} \mathrm{C}\right)$, the viscosity of the bitumen was decreased up to put it on the same value than a conventional bitumen 40/50, while under the melting temperature the viscosity was significantly increased (13).

In order to improve their applicability, two mixtures have been designed at the easiest way with all the materials working together.

\section{Materials and methodology}

The design process was divided in four stages: characterization of materials, analysis of the viscosity of the modified bitumen with and without waxes, dosage of the experimental mixture with the recycled materials but at conventional temperature, and finally characterization of the experimental mixture at reduced temperature with the selected wax.

\subsection{Materials characterization}

53 EAF slag was provided by an authorized waste manager. The origin of RAP is unknown. It is made up of limestone in fine fraction and ophitic aggregate in coarse. The main characteristics of both are gathered in Table 1.

\begin{tabular}{|l|c|l|c|}
\hline \multicolumn{1}{|c|}{ EAF Slag } & Result & \multicolumn{1}{|c|}{ RAP } & Result \\
\hline Specific weight $\left(\mathrm{g} / \mathrm{cm}^{3}\right)$ & 3,821 & Specific weight $\left(\mathrm{g} / \mathrm{cm}^{3}\right)$ & 2,502 \\
Flakiness index & 2 & Flakiness index & 11 \\
Los Angeles coefficient & 18 & Los Angeles coefficient & 24 \\
Water absorption 24 (\%) & 1 & Sand equivalent & 93 \\
Polished stone value (PSV) & 0,59 & Residual bitumen (\%) & 4 \\
Expansiveness & $\sqrt{ }$ & Softening point $\left({ }^{\circ} \mathrm{C}\right)$ & 76,1 \\
Leaching test & $\sqrt{ }$ & Penetration $(0,1 \mathrm{~mm})$ & 13 \\
\hline
\end{tabular}

Table 1. Characteristics of the alternative aggregates

EAF Slag is a hard aggregate useful to work in the surface layer due to its high PSV, being its high density the main difference with the conventional aggregates. It has not had problems of expansiveness or leaching. Regarding the RAP, the Sand Equivalent test was used as a method to analyse if it had been contaminated. The results showed the usual high softening temperature and 61 low penetration.

62 The manufacturing temperature of the selected rubber modified bitumen ranged from $165^{\circ} \mathrm{C}$ to $63175^{\circ} \mathrm{C}$ according the supplier. Table 2 shows its main characteristics.

\begin{tabular}{lc}
\hline \multicolumn{1}{c}{ Property } & Result \\
\hline Penetration $(0,1 \mathrm{~mm})$ & 54 \\
Softening point $\left({ }^{\circ} \mathrm{C}\right)$ & 63 \\
Elastic recuperation $(\%)$ & 58 \\
Relative density $\left(\mathrm{g} / \mathrm{cm}^{3}\right)$ & 1,047 \\
\hline
\end{tabular}


Regarding the additives, different waxes were analysed attending economic criteria. A Fischer-

Tropsch wax with a melting temperature between $90^{\circ} \mathrm{C}$ and $115^{\circ} \mathrm{C}$, and a fatty acid amide wax with a melting point around $140^{\circ} \mathrm{C}$, were finally selected.

The particle size distribution of the mixture was completed with limestone. It was always used in the fine fraction to complete the percentage of RAP until the desired grading size. The density of the limestone was $2,708 \mathrm{gr} / \mathrm{cm}^{3}$ and the sand equivalent coefficient was 78 .

\subsection{Analysis of viscosity}

The test was carried out with a Brookfield viscometer and the container was a $600 \mathrm{ml}$ Low Beaker Griffin. 3\% of each wax by mass of bitumen was incorporated. The mix between wax and bitumen was carried out at $150^{\circ} \mathrm{C}$ with an IKA homogenizer. This process took 5 minutes at $15.000 \mathrm{rpm}$.

The viscosity obtained for the reference bitumen at the manufacturing temperature recommended by the supplier was considered as reference. When the waxes were incorporated the viscosity was measured at different temperatures. The temperature that reached the same viscosity of reference, indicated the decrease of temperature that allow the waxes. These viscosities are relative to the rubber modified bitumen.

\subsection{Dosage of mixture at conventional temperature}

The mixtures were dosed at conventional temperature to ensure that they worked properly without any influence of the wax. The RAP was sieved for the maximum size of the mixture $(16 \mathrm{~mm})$ as the only condition, which means that it was heated as the other aggregates. Its grading size without residual bitumen was considered for the design of the mixtures. The coarse fraction was completed with EAF slag, while limestone completed the fine fraction. The design was make by volume due to the high specific weight of the slag.

\subsection{Characterization of the mixture at reduced temperature}

The same tests used for the design of the mixtures were repeated, but in this case the selected wax was added, and the reduced temperature was used for the manufacturing of the mixes. Thus, the performance and the viability of manufacturing at reduced temperature were studied.

\section{Statistical Analysis}

92 The statistical software Minitab was used to compare the results. The confidence interval considered was $95 \%$ ( $p$-value of 0,05 ). When the results fulfilled a normal distribution and there was homogeneity of variances the T Student test was carried out. Otherwise, the $U$ of Mann-Whitney test was used.

\section{Results and discussion}

The final dosage for each type of mixture is gathered in Table 3. The bitumen percentages were lower than usual due to the high specific weight of the Slag. Initially RAP was going to be used in both

99 mixtures, but its addition to the BBTM11 B discontinuous mixture did not produce a decrease in the 100 final percentage of bitumen, and due to the low percentage of fine aggregates of this type of mixture 
it was finally not considered.

\begin{tabular}{ccc}
\hline Material & AC 16 S & BBTM 11 B \\
\hline Steel slag & 68,80 & 83,00 \\
Limestone & 16,50 & 12,80 \\
RAP & 13,70 & - \\
Filler & 1,00 & 4,20 \\
Bitumen total / Mix & 4,30 & 3,75 \\
New bitumen / Mix & 3,80 & 3,75 \\
\hline
\end{tabular}

Table 3. Percentage by weight of each material

\subsection{Assessment of equi-viscous temperature and workability}

104 105

The viscosity analysis showed that the waxes decrease the bitumen viscosity with rubber when the temperature of the mixture is above the wax melting point (Figure 1 ).

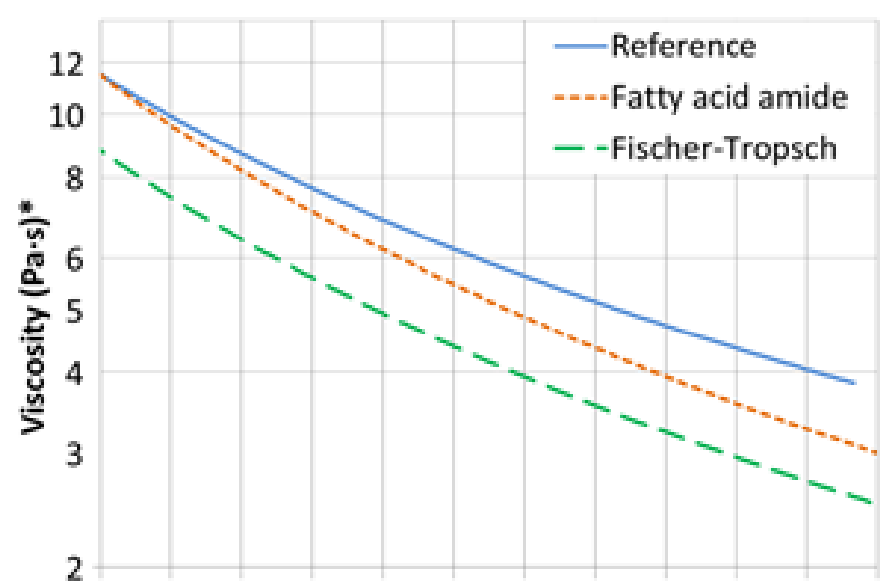

$90100110120130140150160170180190200 \quad 120$ Temperature $\left({ }^{\circ} \mathrm{C}\right)$

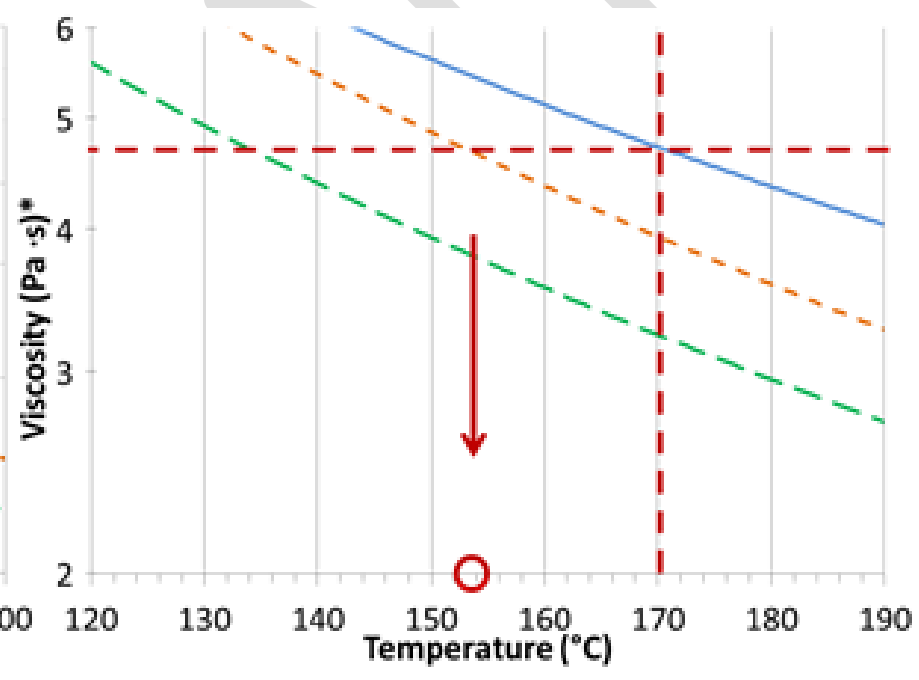

Figure 1. Viscosity test
108

109

110

The Fischer-Tropsch wax decreases more the viscosity of the rubber modified bitumen than the Fatty acid amide wax, supporting the analysis performed by other studies(14), however the Fatty acid wax was selected since around $130^{\circ} \mathrm{C}$ it began to recover the viscosity of the reference mixture, so the resistance against plastic deformation is not compromised. Finally, the reduced temperature was selected considering the reference viscosity at the temperature recommended by the supplier. The new reduced manufacturing temperature was $150^{\circ} \mathrm{C}$. Therefore, a decrease of $20^{\circ} \mathrm{C}$ was achieved by the Fatty acid amide wax.

The energy of compaction was calculated to know if the decrease of temperature resulted in any difference in the compaction process of the mixtures. The workability test (EN $12697-31$ ) was performed with a Controls ICT 76-B0251 machine and three samples of each type of mixture were tested. The model developed by Del Río(15) was used to calculate the accumulated energy per mass unit:

$$
\frac{W}{m}=\sum_{1}^{N} \frac{W_{i}}{m}=\frac{2 \cdot \pi \cdot \alpha \cdot \mathrm{A}}{\mathrm{m}} \sum_{1}^{N} \mathrm{~h}_{\mathrm{i}} \cdot \mathrm{S}_{\mathrm{i}}
$$

120 where $W(\mathrm{KJ})$ is the accumulated energy of compaction, $m(\mathrm{Kg})$ is the mass, $N$ is the total of cycles 121 applied, $\alpha(\mathrm{rad})$ is the inclination angle of the cylindrical sample, $A(\mathrm{~m} 2)$ is the sample area, $h_{i}(\mathrm{~m})$ is 
the height of the sample in each cycle $\mathrm{i}$, and $S_{i}(\mathrm{KN} / \mathrm{m} 2)$ the shear stress measured in each cycle $\mathrm{i}$.

123 The required energy in relation to the compaction for both mixtures is shown in Figure 2.
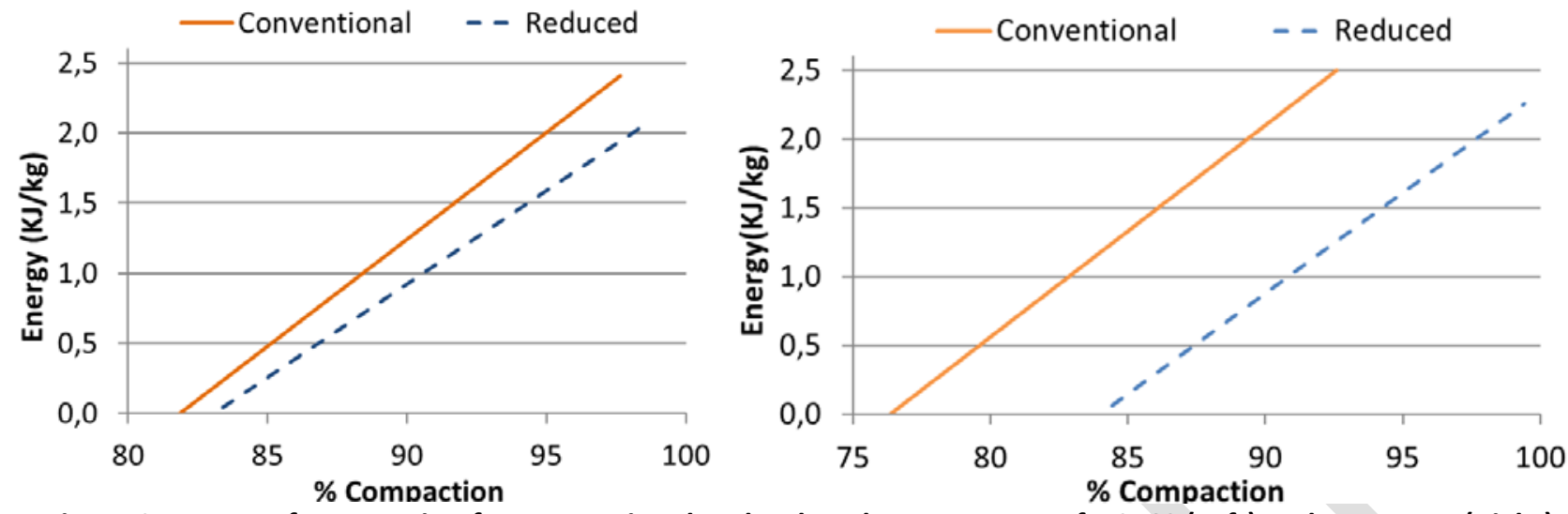

Figure 2. Energy of compaction for conventional and reduced temperature of AC16S (Left) and BBTM11B (Right)

According to the results, the BBTM mixtures require more compaction energy than the AC. This is due to the discontinuity of their particle size distribution, which gives them greater internal friction. Although there is a trend for which the required compaction effort decreases when the wax is incorporated, especially in the case of the BBTM mixtures, the T-Student test showed that there were not significant differences between the mixtures ( $p$-value of 0,141 for AC and 0,690 for BBTM), so the compaction process would not change while the temperature is above the melting point of the fatty acid amide wax.

\subsection{Volumetric and mechanical properties}

The volumetric and mechanical properties were measured through different tests depending on the type of mixture. Four Marshall samples were used for the voids test (EN 12697 - 8) and the Cantabro particle loss test (EN 12697 - 17), eight samples for the water sensitivity test (EN $12697-12$ ), and 11 samples in the stiffness test (EN 12697-26), which was carried out at $20^{\circ} \mathrm{C}$. The Spanish standard for the highest traffic level and warmest area has been considered as the reference for the mechanical performance.

\subsubsection{Asphalt Concrete (AC $16 \mathrm{~S})$}

Table 4 presents the results of voids and water sensitivity tests for the mixtures manufactured at conventional and reduced temperature.

\begin{tabular}{l|l|cc|c}
\cline { 2 - 5 } \multicolumn{2}{l|}{ Temperature } & \multicolumn{1}{c}{ Conventional } & Reduced & Spanish Standard \\
\hline \multirow{2}{*}{ Voids test } & Density $\left(\mathrm{g} / \mathrm{cm}^{3}\right)$ & 2,892 & 2,891 & - \\
EN $12697-8$ & Voids in mixture (\%) & 5,3 & 5,3 & $4-6$ \\
& Voids in aggregates (\%) & 17,2 & 17,2 & $>15$ \\
\hline \multirow{2}{*}{ Water sensitivity test } & I.T.S. (Kp) Dry & 1790,9 & 1555,5 & - \\
EN $12697-12$ & Wet & 1757,7 & 1411,6 & - \\
& I.T.S.R. (\%) & 98 & 91 & $\geq 85$ \\
\hline
\end{tabular}

Table 4. Mechanical properties of AC $16 \mathrm{~S}$ at both temperatures

The results followed a normal distribution and there was homogeneity of variances, so a T-Student test was performed to analyse the results. Table 5 collects the significances obtained. As far the voids test, no differences were found between the mixtures at conventional and reduced temperature. On 
147 the other hand, decreased significantly the indirect tensile strength ratio in the water sensitivity test 148 ( $p$-values under 0,05 ), so it seems that the addition of the wax modifies the adherence between 149 aggregate and bitumen, and the temperature of compaction might affect the indirect tensile strength 150 of the mixtures, even if the viscosity does not change(16). All in all, both mixtures fulfilled the 151 requirements.

\begin{tabular}{ccc}
\cline { 2 - 3 } & Voids test & Water sensitivity test \\
\hline P-value & 0,883 & 0,000 \\
\hline \multicolumn{2}{l}{ Table 5. Significances of the mechanical tests of AC mixture }
\end{tabular}

153 The results of the stiffness are gathered in Table 6. The Spanish standard (according Valencia 154 regulations) considers $3500 \mathrm{MPa}$ as the minimum value at $10 \mathrm{~Hz}$.

\begin{tabular}{|c|cc|cc|cc|cc|}
\cline { 2 - 8 } \multicolumn{1}{c|}{} & \multicolumn{3}{c|}{ Conventional temperature } & \multicolumn{3}{c|}{ Reduced temperature } \\
\hline $\begin{array}{c}\text { Frequency } \\
(\mathrm{Hz})\end{array}$ & $\begin{array}{c}\text { Dynamic Modulus } \pm \\
\text { Deviation } \\
\text { (MPa) }\end{array}$ & \multicolumn{2}{|c|}{$\begin{array}{c}\text { Phase angle } \pm \\
\text { Deviation } \\
\left({ }^{\circ}\right)\end{array}$} & $\begin{array}{c}\text { Dynamic Modulus } \pm \\
\text { Deviation } \\
(\mathrm{MPa})\end{array}$ & $\begin{array}{c}\text { Phase angle } \pm \\
\text { Deviation } \\
\left({ }^{\circ}\right)\end{array}$ \\
\hline 0,1 & 1827 & 367 & 24,7 & 2,0 & 2690 & 291 & 25,3 & 0,9 \\
0,2 & 2128 & 404 & 24,4 & 1,8 & 3152 & 333 & 24,7 & 0,8 \\
0,5 & 2633 & 464 & 24 & 1,7 & 3930 & 401 & 23,8 & 0,7 \\
1 & 3073 & 511 & 23,3 & 1,6 & 4612 & 459 & 23 & 0,7 \\
2 & 3597 & 563 & 22,6 & 1,5 & 5383 & 526 & 21,8 & 0,6 \\
5 & 4411 & 638 & 21,5 & 1,4 & 6555 & 604 & 20,2 & 0,6 \\
8 & 4877 & 674 & 20,7 & 1,3 & 7221 & 673 & 19,3 & 0,6 \\
10 & 5094 & 670 & $\mathbf{2 0 , 4}$ & 1,4 & 7528 & 699 & 18,9 & 0,6 \\
20 & 5930 & 821 & 20,8 & 3,1 & 8597 & 900 & 18,4 & 2,9 \\
30 & 6587 & 852 & 19,8 & 1,6 & 10021 & 888 & - & 1,9 \\
\hline
\end{tabular}

Table 6. Stiffness tests of AC mixtures at conventional and reduced manufacturing temperature

156 The $U$ test of Mann-Whitney concluded that the differences between the mixtures were significant 157 (with a p-value of 0,00 ). Therefore, it might be said that the incorporation of the fatty acid amide wax 158 produces a significant increase of the stiffness, which can be linked with the recovery of viscosity suffered by the Fatty acid amide wax when it is below its melting point (Figure 1).

The properties of the discontinuous mixture are shown in Table 7, in which the results of the voids test, the water sensitivity test, and the Cantabro particle loss test for both temperatures are included.

\begin{tabular}{l|l|cc|c}
\cline { 2 - 5 } & \multicolumn{1}{c}{ Temperature } & Conventional & Reduced & Spanish standard \\
\hline Voids test & Density (g/cm $\left.{ }^{3}\right)$ & 2,743 & 2,689 & - \\
EN 12697-8 & Voids in mixture (\%) & 16,8 & 18,1 & $12-18$ \\
\hline \multirow{2}{*}{ Water sensitivity test } & I.T.S. Dry & 1169,6 & 1012,8 & - \\
EN 12697 - 12 & (Kp) Wet & 1084,7 & 913,4 & - \\
& ITSR (\%) & 93 & 90 & $\geq 90$ \\
\hline Cantabro particle loss test & Mass (\%) & 9,8 & 11,8 & $\leq 15^{*}$ \\
EN 12697-17 & & &
\end{tabular}

Table 7. Mechanical properties of BBTM 11 B at both temperatures

164 The analysis showed that the mixture manufactured at reduced temperature had significantly more 
voids, although this increase is small. In fact, the mixtures should have an equivalent percentage of voids according to the viscosity and workability test. The ITSR of the water sensitivity test decreased, which is in line with the result of the AC, although in this case it can be due to the slightly higher percentage of voids. There were not significant differences in the Cantabro particle loss test. The performance of both mixtures was good and similar to a conventional BBTM. The results had a normal distribution and homogeneity of variances, so T-Student was used to analyse them. The significances are presented in Table 8.

\begin{tabular}{cccc}
\cline { 2 - 4 } & Voids test & Water sensitivity test & Particle loss test \\
\hline P-value & 0,000 & 0,009 & 0,254 \\
\hline
\end{tabular}

Table 8. Significances of the mechanical tests of BBTM mixture

The stiffness of both mixtures is presented in Table 9. The minimum value according to the Valencia standard for this type of mixture at $10 \mathrm{~Hz}$ is $2500 \mathrm{MPa}$.

\begin{tabular}{|c|cc|cc|cc|cc|}
\cline { 2 - 8 } \multicolumn{1}{c|}{} & \multicolumn{3}{c|}{ Conventional temperature } & \multicolumn{3}{c|}{ Reduced temperature } \\
\hline $\begin{array}{c}\text { Frequency } \\
(\mathrm{Hz})\end{array}$ & $\begin{array}{c}\text { Dynamic Modulus } \pm \\
\text { Deviation } \\
(\mathrm{MPa})\end{array}$ & $\begin{array}{c}\text { Phase angle } \pm \\
\text { Deviation } \\
\left({ }^{\circ}\right)\end{array}$ & $\begin{array}{c}\text { Dynamic Modulus } \pm \\
\text { Deviation } \\
(\mathrm{MPa})\end{array}$ & $\begin{array}{c}\text { Phase angle } \pm \\
\text { Deviation } \\
\left({ }^{\circ}\right)\end{array}$ \\
\hline 0,1 & 570 & 126 & 35,4 & 1 & 618 & 95 & 38,1 & 0 \\
0,2 & 714 & 157 & 34,8 & 1 & 777 & 123 & 37,8 & 0 \\
0,5 & 969 & 212 & 34,3 & 1 & 1076 & 169 & 37,1 & 0 \\
1 & 1216 & 265 & 33,5 & 1 & 1370 & 214 & 36,2 & 1 \\
2 & 1525 & 334 & 32,4 & 1 & 1748 & 272 & 34,9 & 1 \\
5 & 2048 & 445 & 30,6 & 1 & 2395 & 367 & 32,7 & 1 \\
8 & 2368 & 515 & 29,5 & 1 & 2794 & 424 & 31,3 & 1 \\
10 & 2540 & 559 & 29,0 & 1 & 2993 & 452 & 30,7 & 1 \\
20 & 3115 & 674 & 28,1 & 2 & 3716 & 586 & 28,4 & 1 \\
30 & 3455 & 709 & 26,8 & 1 & 4273 & 605 & 28 & 1 \\
\hline
\end{tabular}

Table 9. Stiffness tests of BBTM mixtures at conventional and reduced manufacturing temperature

The results of the mixture at reduced temperature showed a slight increase of the dynamic modulus and the phase angle, although in this case the $U$ test of Mann-Whitney resulted in no significant differences (the p-value obtained in the test was 0,094). Therefore, the increase of the stiffness showed in the AC cannot be definitively confirmed, even if the stiffness always trends to increase.

\subsection{Performance related tests}

The wheel tracking test (EN 12697 - 22) and the fatigue resistance test (EN 12697-24) were carried out to analyse the behaviour of the mixtures. The former was performed with three slabs, while the latest was done with 11 samples at $20^{\circ} \mathrm{C}$ at $30 \mathrm{~Hz}$. The fatigue resistance laws were calculated with the following equation:

$$
\varepsilon(\mathrm{m} / \mathrm{m})=\mathrm{a} \cdot 10^{-3} \cdot N(\text { Cycles })^{\mathrm{b}}
$$

The failure criterion was the cycle $(N)$ for which the sample presented a stress of $S_{0} / 2$, being $S_{0}$ the initial stress for the imposed strain $(\varepsilon)$ after 100 initial cycles. This is equivalent to decreasing the initial stiffness of the material until its half.

\subsubsection{Asphalt concrete (AC $16 \mathrm{~S}$ )}

The resistance against plastic deformation is gathered in Table 10. The thickness of the slabs was $50 \mathrm{~mm}$. 


\begin{tabular}{l|cc|c}
\hline \multicolumn{1}{c}{ Temperature } & Conventional & Reduced & Spanish standard \\
\hline Slope $(\mathrm{mm} / 1000$ cycles) & 0,04 & 0,03 & $\leq 0,07$ \\
Tracking depth $(\mathrm{mm})$ & 2,1 & 2,1 & - \\
\hline
\end{tabular}

Table 10. Wheel tracking test result of $\mathrm{AC} 16 \mathrm{~S}$ at both temperatures

The resistance against plastic deformation of the mixture manufactured at reduced temperature increased, but the p-value of T-Student test was 0,090. Therefore, this result cannot be statically confirmed.

The results of the fatigue resistance test are presented in the following table (Table 11). There is not any requirement about this test in the Spanish standard for conventional mixtures, although the minimum strain-characteristic (the strain at $10^{6}$ cycles) for the high modulus mixtures is $100 \mu \mathrm{m} / \mathrm{m}$.

\begin{tabular}{ccccc}
\hline Temperature & $\mathrm{S}_{0}(\mathrm{MPa})$ & strain-characteristic $(\mu \mathrm{m} / \mathrm{m})$ & Fatigue line & $\mathrm{R}^{2}$ \\
\hline Conventional & 5290 & 184,9 & $\varepsilon=1,395 \cdot 10^{-3} \cdot \mathrm{N}^{-0,1463}$ & 0,93 \\
Reduced & 8530 & 168,4 & $\varepsilon=1,899 \cdot 10^{-3} \cdot \mathrm{N}^{-0,1754}$ & 0,88 \\
\hline
\end{tabular}

According to the results obtained, the resistance to fatigue with the fatty acid amide wax is lower than the resistance of the mixture at conventional temperature, although it showed a good performance. Besides, its initial modulus is higher, which is coherent with the stiffening previously commented. Nevertheless, the analysis showed that the decrease is not statistically significant (a pvalue of 0,733 was obtained through the $U$ test of Mann-Whitney), so it cannot be concluded that the addition of the wax reduces the fatigue resistance. This is important because the increase of the fatigue resistance is one of the greatest advantages of rubber modified bitumen as compared to a conventional binder(17).

\subsubsection{Very thin asphalt concrete (BBTM 11 B)}

The resistance against plastic deformation of the non-continuous mixture is presented in Table 12. The thickness of the slabs was $40 \mathrm{~mm}$.

\begin{tabular}{l|cc|c}
\hline \multicolumn{1}{c|}{ Temperature } & Conventional & Reduced & Spanish standard \\
\hline $\mathrm{mm} / 1000$ cycles & 0,06 & 0,06 & $\leq 0,07$ \\
Tracking depth $(\mathrm{mm})$ & 2,4 & 2,3 & - \\
\hline
\end{tabular}

Table 12. Wheel tracking test results of BBTM $11 \mathrm{~B}$ at both temperatures

There were not differences in the wheel tracking test. The addition of the wax had not any significant influence in the resistance against plastic deformations (a p-value of 0,565 was obtained), so this property is not modified by the addition of wax and the manufacturing at reduced temperature.

214 The results of the fatigue resistance test are shown in table 13.

\begin{tabular}{ccccc}
\hline Temperature & $\mathrm{S}_{0}(\mathrm{MPa})$ & strain-characteristic $(\mu \mathrm{m} / \mathrm{m})$ & Fatigue line & $\mathrm{R}^{2}$ \\
\hline Conventional & 3120 & 168,3 & $\varepsilon=3,325 \cdot 10^{-3} \cdot \mathrm{N}^{-0,2159}$ & 0,93 \\
Reduced & 3530 & 147,6 & $\varepsilon=3,603 \cdot 10^{-3} \cdot \mathrm{N}^{-0,2313}$ & 0,96 \\
\hline
\end{tabular}

216 It can be seen how the mixture showed less resistance against fatigue, as in the case of the AC mixture, the characteristic strain is lower and $S_{0}$ is higher for the mixture manufactured at reduced temperature with the fatty acid amide wax. Thus, although there were not significant differences between the mixtures ( $U$ test of Mann-Whitney resulted a significance of 0,678 ), in both cases, AC 
and BBTM, the fatigue resistant was slightly decreased, which might be related with the possible stiffening of the mixtures due to the wax addition.

\section{Conclusions}

All mixtures, at conventional and reduced temperature, have fulfilled the requirements at laboratory level to be used in surface layers, in wherever climatic area and under the highest traffic level of the Spanish standards with more than $80 \%$ of recycled aggregates. Therefore, it might be said that the limits to the manufacturing of bituminous mixtures with high rates of recycled material nowadays are not technical.

The manufacturing temperature has been decreased by $20^{\circ} \mathrm{C}$ through the incorporation of the fatty acid amide wax. Consequently, the manufacturing conditions of the bitumen modified with rubber are similar to a conventional mixture with a bitumen 50/70.

The analysis of the compaction energy has shown that there are not significant differences among the mixtures, so it seems that manufacturing at reduced temperature does not imply modifying the compaction process while the mixture temperature is above the melting temperature of the wax.

The addition of the fatty acid amide wax has shown a slight increase of the resistance against plastic deformation (although it has not been statistically meaningful), and a significant decrease of the ITSR in the water sensitivity test. Besides, the stiffness of the mixtures modified with the fatty acid amide wax slightly increased, and the results have not shown significant differences in the fatigue resistant test, although it seems that it tends to decrease. Therefore, the mixtures modified with waxes would be more appropriate for warm areas, where rutting is one of the greatest problems and it is less likely that problems of cracking arise.

\section{Acknowledgements}

GREENROAD is a project financed by the "LIFE+" program of the European Union, with reference number LIFE $11 \mathrm{ENV/ES/623.} \mathrm{This} \mathrm{project} \mathrm{was} \mathrm{carried} \mathrm{out} \mathrm{by} \mathrm{a} \mathrm{consortium} \mathrm{coordinated} \mathrm{by} \mathrm{COPSESA}$ (Constructora Obras Públicas San Emeterio S.A.) and integrated by GITECO (Construction Technology Applied Research Group, University of Cantabria) and the Department of Road Construction from the Santander City Council. The authors wish to acknowledge and especially thank Laboratory of Science and Engineering of Materials of the University of Cantabria (LADICIM), CODEFER S.L., Global Steel Wire S.A. (GSW), and Unión Derivan S.A. (UNDESA) for their collaboration.

\section{References}

1. RODRÍGUEZ-ALLOZA, A.M., GALLEGO, J. and PÉREZ, I. Study of the Effect of Four Warm Mix Asphalt Additives on Bitumen Modified with 15\% Crumb Rubber. Construction and Building Materials, 2013, vol. 43. pp. 300-308 SCOPUS. ISSN 09500618.

2. D'ANGELO, J., et al. Warm-Mix Asphalt: European Practice. Federal Highway Administration, U.S. Department of Transportation. ed., , 2008 FHWA-PL-08-007.

3. ROWE, G.M., BARRY, J. and CRAWFORD, K. Evaluation of a $100 \%$ Rap Recycling Project in Fort Wayne, Indiana. Kluwer Academic Publishers, 2016 SCOPUS. ISBN 22110844. DOI 10.1007/978-94017-7342-3_75. 
4. LO PRESTI, D., JIMÉNEZ DEL BARCO CARRIÓN, A., AIREY, G. and HAJJ, E. Towards $100 \%$ Recycling of Reclaimed Asphalt in Road Surface Courses: Binder Design Methodology and Case Studies. Journal of Cleaner Production, 2016, vol. 131. pp. 43-51 SCOPUS. ISSN 09596526.

5. EL SHARKAWY, S.A., WAHDAN, A.H. and GALAL, S.A. Utilisation of Warm-Mix Asphalt Technology 262 to Improve Bituminous Mixtures Containing Reclaimed Asphalt Pavement. Road Materials and Pavement Design, 2016. pp. 1-30 SCOPUS. ISSN 14680629.

6. AHMED, T.A., LEE, H. and BAEK, C.M. Evaluation of Laboratory and Field Warm Mix Asphalt Mixtures with High Contents of Reclaimed Asphalt Pavement. Nikolaides A.F. ed., CRC Press/Balkema, 10 June 2015 through 12 June 2015, 2015 SCOPUS. ISBN 9781138028661 (ISBN).

7. Centro de estudios y experimentación de obras públicas (CEDEX). Ficha Técnica. Escorias De Acería De Horno De Arco Eléctrico. Ministerio de Fomento. Ministerio de medio ambiente y medio rural y marino., 2011.

8. PASETTO, M. and BALDO, N. Experimental Evaluation of High Performance Base Course and Road Base Asphalt Concrete with Electric Arc Furnace Steel Slags. Journal of Hazardous Materials, 2010, vol. 181, no. 1-3. pp. 938-948 SCOPUS.

9. BEHNOOD, A. and AMERI, M. Experimental Investigation of Stone Matrix Asphalt Mixtures Containing Steel Slag. Scientia Iranica, 2012, vol. 19, no. 5. pp. 1214-1219 SCOPUS.

10. PASETTO, M. and BALDO, N. Fatigue Behavior Characterization of Bituminous Mixtures made with Reclaimed Asphalt Pavement and Steel Slag. Procedia - Social and Behavioral Sciences, 10/3, 2012, vol. 53, no. 0. pp. 297-306 ISSN 1877-0428.

11. PASETTO, M. and NICOLA, B. Asphalt PAvements R.Y. KIM ed., Volume 1 ed. London: Taylor \& Francis Group, 2014 Resistance to Permanent Deformation of Base Courses Asphalt Concretes made with RAP Aggregate and Steel Slag, pp. 1199-1208 ISBN 978-1-138-02693-3.

12. CEDEX, Centro de estudios y experimentación de obras públicas. Manual De Empleo De Caucho De NFU En Mezclas Bituminosas. Ministerio de Fomento and Ministerio de medioambiente eds., , Mayo de 2007, 2007.

13. GIL REDONDO, S. and HERRERO, O. Betún Modificado Con Polvo De Neumático Y Ceras, En Mezcla M-10 Con Fibras. Asefma, 2009. pp. 225-235.

14. RODRÍGUEZ-ALLOZA, A.M., et al. High and Low Temperature Properties of Crumb Rubber Modified Binders Containing Warm Mix Asphalt Additives. Construction and Building Materials, 2014, vol. 53. pp. 460-466 SCOPUS. ISSN 09500618.

15. DEL RÍO PRAT, M. Estudio De Los Procesos De Compactación Y Post-Compactación De Mezclas Bituminosas Empleando Nuevos Índices Energéticos: Aplicación a Mezclas De Alto Módulo Que Contienen Cantos Rodados. CALZADA PÉREZ, Miguel Ángel and VEGA ZAMANILLO, Ángel eds., Santander: Universidad de Cantabria, 2011.

16. MORENO RUBIO, J. Efecto De Equipo Y Procedimiento De Medida En La Determinación Del Módulo Resiliente Y Resistencia a Tracción Indirecta De Las Mezclas Bituminosas. MARTínEZ REGUERO, Adriana Haydée ed., Barcelona: Universitat Politécnica de Catalunya, 2006.

17. XIAO, F., AMIRKHANIAN, S.N., SHEN, J. and PUTMAN, B. Influences of Crumb Rubber Size and Type on Reclaimed Asphalt Pavement (RAP) Mixtures. Construction and Building Materials, 2009, vol. 23, no. 2. pp. 1028-1034 SCOPUS. ISSN 09500618. 